Revista Eletrônica Geografar, Curitiba, v. 2, Resumos do VI Seminário Interno de Pós-Graduação em Geografia, p. 49-49. Junho/2007

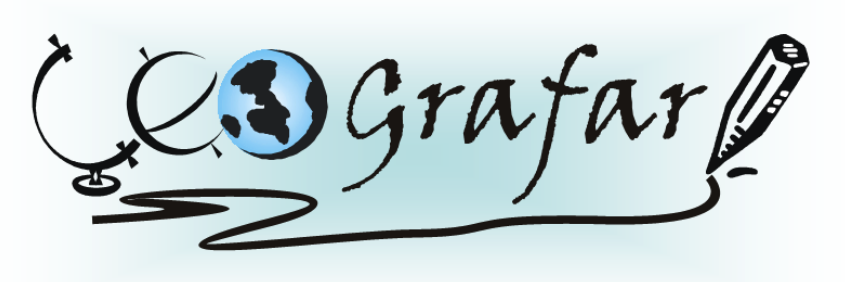

Revista Eletrônica do Programa de Pós-Graduação em Geografia - UFPR

\title{
A INFLUÊNCIA DA RADIAÇÃO ULTRAVIOLETA NA INCIDÊNCIA DO CANCÊR DE PELE NO ESTADO DO PARANÁ
}

\author{
MÁRCIA MARIA FERNANDES DE OLIVEIRA ${ }^{1}$
}

No Brasil o câncer de pele é o mais freqüente, correspondendo a aproximadamente $25 \%$ de todos os tumores diagnosticados em todas as regiões geográficas do país. Câncer é o nome dado a um conjunto de mais de cem doenças que têm em comum o crescimento desordenado (maligno) de células que invadem os tecidos e órgãos, podendo espalhar-se (metástase) para outras regiões do corpo. O aumento de novos casos de câncer de pele constitui preocupação crescente de todos os povos e a radiação ultravioleta proveniente do sol é o seu maior agente etiológico, donde a necessidade da abordagem geográfica do problema. O recorte espacial deste estudo abrange o Estado do Paraná, onde o câncer de pele tem maior incidência quando comparado às outras regiões do país. Um dos métodos utilizado neste trabalho está baseado no mapeamento dos hospitais oncológicos das cidades do Estado, onde dados como procedência, idade, sexo, profissão, habitação, escolaridade e nível social são analisados; em seguida, identificam-se as interações entre mortalidade e as condições climáticas, a evolução das condições climáticas e sua interação com a evolução dos casos de câncer de pele. No final desta pesquisa serão traçados cenários de evolução desta doença para a região, bem como levantadas sugestões para subsidiar políticas públicas voltadas ao equacionamento de problemas relativos à incidência da doença. Sua abordagem essencial concerne na análise da inter-relação entre as condições climáticas e o câncer de pele, com ênfase na radiação ultravioleta, pois esta parece ter uma ligação direta no aparecimento do câncer de pele. Como hipótese poderíamos lançar que a radiação ultravioleta e as condições da intensificação do aquecimento climático são favoráveis ao câncer de pele, particularmente quando associadas às condições de vida da população de baixa renda (maior mortalidade) e ao aquecimento global que se manifesta nesta escala.

Palavras-chave: Radiação Ultravioleta - Câncer de Pele - Estado do Paraná.

${ }^{1}$ Doutoranda em Geografia - UFPR - email: marciamfoliv@ufpr.br Orientadora: INÊS MORESCO-DANNI OLIVEIRA 